\title{
The Value of Multiple Perspectives
}

Problem-solving and Critique in the Evaluation of Social Acceptance Research - A Response to M. Wolsink

James Gaede ${ }^{a}$, Ian H. Rowlands ${ }^{b}$

${ }^{a, b}$ School of Environment, Resources and Sustainability, University of Waterloo 200 University Ave, W., Waterloo, Ontario, Canada N2L 3G1

Corresponding Author: James Gaede, jrgaede@uwaterloo.ca

Published in Energy Research \& Social Science, Vol. 48, February 2019, pp. 262-268

\begin{abstract}
Established social acceptance scholar Maarten Wolsink recently published in these pages a critique of an earlier paper of ours, also published in ERSS. In this response, we will review some of Wolsink's specific methodological concerns about our original paper, conduct some preliminary analysis to test their validity, and address the issue of 'objects of acceptance' thereafter. Suffice it to say, while we find some evidence to support Wolsink's claims and personally agree (mostly) with Wolsink's broader discussion of what social acceptance is (or, rather, should be understood as) and what research on it should aim to address, we nevertheless respectfully defend the legitimacy of both our methodological design and findings within the context of the much more limited, practical aims than we have been read to have.

\section{Keywords}

social acceptance; research methodology; energy technology; institutions;

Acknowledgements: Research made possible by the financial support of the Natural Sciences and Engineering Research Council of Canada (NSERC) as part of the NSERC Energy Storage Technology (NEST) Network. 
We read with great interest (as well as honour and gratitude) established social acceptance scholar Maarten Wolsink's recent critique of - and expansion upon - our 2017 ERSS article, "Visualizing social acceptance research: A bibliometric review of the social acceptance literature for energy technology and fuels". Not only do we welcome and sincerely appreciate Wolsink's criticisms, informed by his deep familiarity with the study of social acceptance (indeed, a depth of knowledge that we cannot match), we largely agree with him. What exactly we agree about deserves some discussion, however. We would like to thank the editors of ERSS for providing us with this opportunity to issue a response to Wolsink's concerns.

In his piece, Wolsink makes two primary arguments against our paper:

1) The methodological design of our research limited our ability to accurately characterize the substance and direction of the field we sought to analyze, and;

2) Trends we identify in our discussion are (if real) indicative of a regression to an antiquated understanding of social acceptance and/or detrimental to the continued development of the study of social acceptance

It may appear that these two claims are at odds with each other - how can our findings simultaneously be artefacts of poor research design, but also harbingers of a larger rot spreading through the field of social acceptance research? Wolsink's answer is that our work, and much of the current research we analyze in our original paper, does not properly conceive of either the "object of acceptance" or acceptance itself (viz., mistaking it for the "mere" aggregation of individual perceptions or attitudes, and not as the complex "bundle of processes of decision-making on issues concerning the promotion of - or counteraction against - new phenomena and new elements in the transformation of energy systems" (Wolsink, 2018, p. 287)).

In this response, we will review some of Wolsink's specific methodological concerns about our original paper, conduct some preliminary analysis to test their validity, and address the issue of 'objects of acceptance' thereafter. Suffice it to say, while we find some evidence to support Wolsink's claims and personally agree (mostly) with Wolsink's broader discussion of what social acceptance is (or, rather, should be understood as) and what research on it should aim to address, we nevertheless respectfully defend the legitimacy of both our methodological design and findings within the context of the much more limited, practical aims than we have been read to have.

\section{Not another framework}

The idea to conduct a bibliometric analysis of social acceptance literature was borne of a research program to examine the social acceptance of energy storage. Wishing to familiarize ourselves with the state-of-the-art in the field, and given the virtual non-existence of other studies looking at the social acceptance of energy storage specifically (though this is changing rapidly now), we thus set out to survey the literature in the hope we could use this review to build a comprehensive framework of the most salient social acceptance issues facing energy storage, and help identify the most fundamental insights and findings of the field for these issue areas. At the very least, such an endeavor would help chart a course for future empirical case research on the acceptance of energy storage.

We soon realized that 'another framework' was not what we should be working toward (the original title of our paper was actually "Not another framework"). Our preliminary review found that concerns 
about the methodological and theoretical rigor of a highly diverse field and of some of its core concepts are long standing, as there was already a number of influential papers in the field that had sought to address these issues. Often, such papers conclude with a call-to-action on what needs to happen to strengthen the field. As we wrote in our 2017 paper:

\begin{abstract}
Reviews and frameworks are useful for combining and condensing a wide range of research into a single, comprehensive structure, highlighting generalizable findings, pointing out gaps or weaknesses in a body of literature, and suggesting future directions for research. In short, they seek to produce order out of (what is perceived as) disorder and - intentionally or not - seek to enforce that order on future research in the field.(James Gaede \& Rowlands, 2018, p. 142)
\end{abstract}

Though we did not and do not take issue with such an objective from an academic standpoint, this is nevertheless not what we wanted to achieve. We did not want to engage in conceptual disputes about the nature of social acceptance, nor did we wish to suggest any particular course of action for the field in general. Rather, we wanted as comprehensive and as impartial an overview of the field as was possible - something that would be practically useful for categorizing, reviewing and conducting research on the social acceptance of emerging technology, but without the theoretical or interpretative depth of a conventional literature review, nor the prescriptive intent of many frameworks.

Bibliometric analysis seemed well placed to accomplish this task, and the objective of the paper evolved accordingly: to produce a visualization of the knowledge domain of social acceptance of energy technology and fuels (more on this below), such that we could provide some insight into the structure and evolution of influence in the field, the current "research fronts" and their respective intellectual bases, and to evaluate the degree to which all of this corresponded with existing influential frameworks and calls-to-action (particularly for collaboration and interdisciplinary dialogue) in the field. We utilized bibliographic coupling (which draws connections between works in our database every time they cite the same source) to identify research fronts, and we used co-citation analysis (which draws connections between the cited references everything they are used together) to identify the intellectual bases. Our reasoning (supported by current academic literature) was that bibliographic coupling would be better placed (?) to analyze current and emerging groups in more recent literature, and co-citation analysis better for investigating heritage since it necessarily (and vastly) broadens the base of literature that informs current research. Our initial dataset contained 857 articles and the citation network contained 31,731 sources.

We concluded with three main observations:

1) The centre of influence across the field appeared to be shifting toward "an interdisciplinary combination of environmental psychology, economics and 'contextual' analysis" and a broader concern "with any or all energy technologies that would or could be part of a transition to a lower-carbon energy future", rather than renewable energy specifically;

2) Current research is grouped more by technology and intellectual heritage than by the kind of acceptance in question (e.g., community, market, sociopolitical);

3) That early calls to "marry the social and psychological approaches" to the study of social acceptance had been heeded, and interdisciplinary dialogue was taking place, though mainly at 
the "individual-level interaction between contextual and psychological factors", and "absent any consideration of political motivations for behavior" (James Gaede \& Rowlands, 2018, sec. 5)

We will not review in any more detail the findings or conclusions of our 2017 paper, except where relevant to the specific criticisms leveled by Wolsink, to which we now turn.

\section{Wolsink's Critique}

As noted above, Wolsink advances two primary arguments against our findings (an incomplete or poorly constructed dataset and, consequently, interpretations of that data that are of questionable legitimacy). The 'canvas' on which these critiques are drawn is Wolsink's own understanding of the concept of social acceptance and what a social acceptance research programme should look like - understandings which he suggests we miss or fail to account for because of bias in the dataset toward a different, antiquated notion of social acceptance.

Below we will review some of his specific concerns about our methodological design, our conceptualization of acceptance and our interpretation of the data, before turning in the final section toward a discussion of his larger claims against some of the literature we cited as influential and, as such, his arguments about social acceptance as a concept and a research programme.

\section{Bias, or Balance?}

Wolsink claims that our dataset is biased, and thus not a reliable starting point to conduct a bibliometric analysis of the literature on social acceptance. There are several elements to this claim:

1) Our use of Web of Science and not Scopus prohibits a fuller consideration of social science

2) Web of Science expanded its indices substantially post-2000, thus making our observation that the literature expanded greatly post-2000 spurious (though not incorrect);

3) Web of Science is "known for countless systematic errors", a claim supported only with a footnote noting multiple different author name spellings, but presumably extendable to suggest that the specific numbers we give for citation counts are inaccurate (note: we did conduct substantial author name deduping in our original analysis to attempt to correct inconsistent spellings);

4) Because of a bias toward more recent literature, we miss the true origins of social acceptance research (in nuclear power and risk studies in the 1960s and 1970s);

5) More severely, our failure to include "institutions" and similar terms in our search criteria misses the true "take off" in the social acceptance literature around this topic in the early 2000s (e.g., (Unruh, 2000));

6) Wolsink takes particular issue with our decision to restrict our dataset to studies classified as "Energy and Fuels", arguing that we do not justify that choice and that the inclusion of 'fuels' specifically is concerning, since "why should fuels, which have been used for a long time and are still dominant define the boundaries of an investigation on social acceptance of new practices, ideas and technologies" (Wolsink, 2018, p. 289)

Some of Wolsink's concerns about the reliability of our dataset revolve around our decision to use only Web of Science (WOS), rather than (or as well as) Scopus. While there is not the place to comprehensively do so here, out of interest we did go back and attempt to conduct a similar search 
using Scopus to evaluate his concerns 1 through 4 . We will address items 5 and 6 in the following section.

Replicating our search parameters exactly was difficult - Scopus does not allow for filtering by bibliographic indices nor does it have the same research categories, so our initial results for the same search criteria as we used in our earlier paper returned over 5000 results (many of which appeared to be in the natural sciences). To best approximate social scientific research on the search parameters (as we had wished to in our 2017 paper) we narrowed our search criteria to the energy, environmental studies, social sciences, economics/econometrics/finance, and business/management/accounting research categories (notably, this is a more expansive criteria than we used in our original paper, but we consider it fair due to the inability to search only the Social Sciences Citations Index with Scopus). The result was a dataset approximately twice the size of our original one: 1877 documents compared to 857 in our original dataset. ${ }^{1}$

We then filtered both the Scopus and the WOS lists to documents with DOIs to compare the uniqueness of each set (the size of each dataset after filtering was 1450 in Scopus, and 834 in WOS, 1765 of which were unique (suggesting 519 documents shared between both WOS and Scopus)). Of the unique DOls, 315 appeared unique to the WOS dataset and 931 unique to the Scopus dataset. Wolsink appears correct in suggesting that Scopus' coverage is broader.

One of Wolsink's criticisms is that WOS prejudices the analysis to more recent research and thereby miss the origins of the field in mid-1960s' studies of nuclear power. To some extent, he is correct here as well. The Scopus dataset (before filtering to DOI records only) has publications going back to 1968, though this is a paper entitled "The post-war mode of development of the European petrochemical industry" by Doll-Steinberg and Moss - not a nuclear power paper, evidently (Doll-Steinberg \& Moss, 1968). In total, only 23 pre-1980 sources were included in this dataset. As to the overall trend in research, the Scopus database shows a similar "take-off" post-2000. In fact, we find $82.5 \%$ of documents in the Scopus dataset were published post-2000, and as Figure 1 indicates, the most dramatic take-off occurs post-2006 (94\% of articles in our original dataset were published post-2000).

\footnotetext{
${ }^{1}$ Notably, in rerunning our original search at WOS, we received 858 results rather than 857 . The paper that was missing in our original analysis was "The user-value of rural electrification: An analysis and adoption of existing models and theories", by S. Hirmer and H. Cruickshank (Hirmer \& Cruickshank, 2014). We have no explanation for why this paper was not included in our original dataset - perhaps it was added to WOS subsequent to our analysis, or it may have been a copy error in transferring the data to Sci2, the program we used to analyse the data. We have no reason to believe that this one paper would have swayed our results differently. Consequently, we will continue to refer to our original database as including 857 results.
} 


\section{SOCIAL ACCEPTANCE PUBLICATIONS BY YEAR \\ SCOPUS VS WOS DATASET}

250

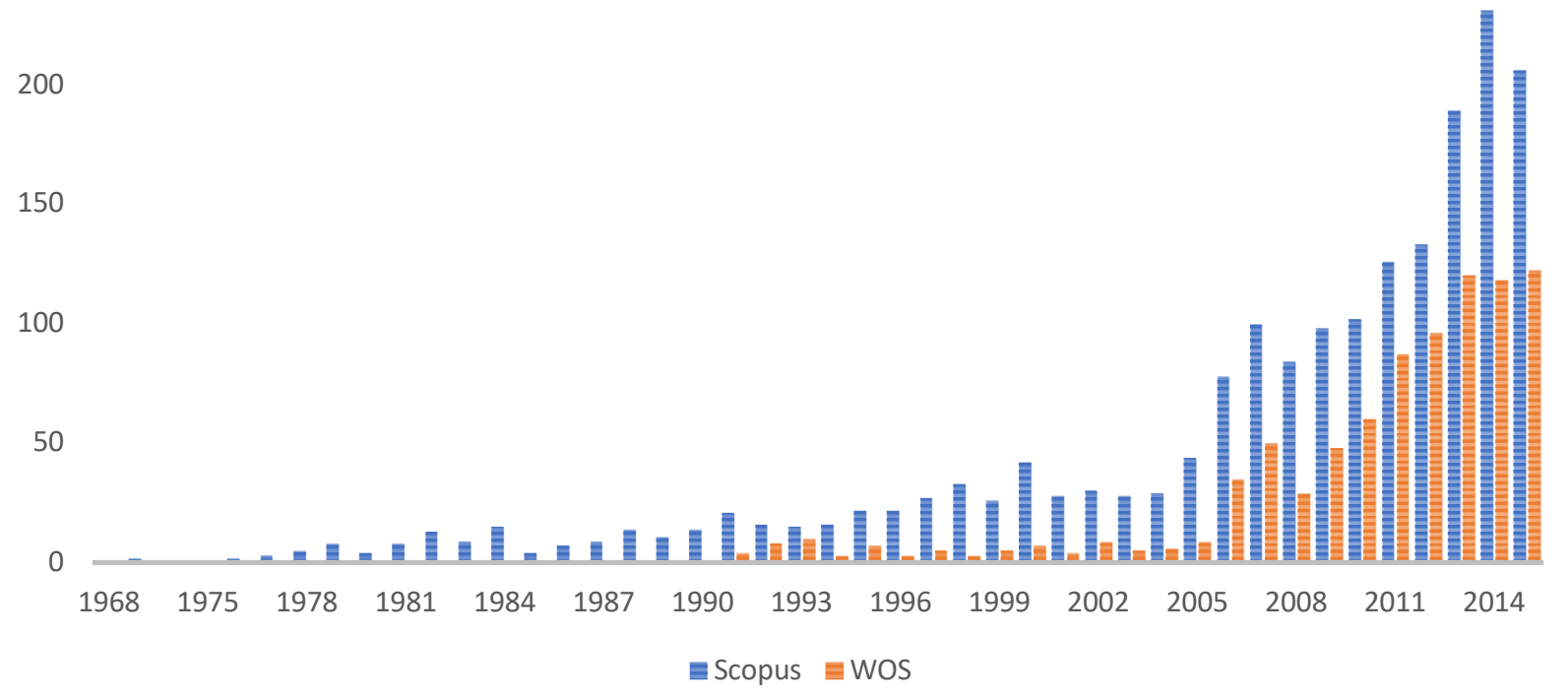

What of the "countless systematic errors" in the WOS dataset that may have undermined our descriptive analysis of influence by authors and journals? Our original dataset's top authors were M. Wolsink (7 publications), J. Ladenburg (6), Devine-Wright (4), CR Jones (4), and JR Eiser (4). The top 5 in our Scopus dataset were Devine-Wright (8), S. Shackley (8), A. Verbruggen (8), Wolsink (7) and N. Snow (7) (CR Jones was listed on 5 papers, Ladenburg on 1, and Eisner did not appear at all). Our original WOS dataset contained publications from 33 journals, and we found Energy Policy, Renewable and Sustainable Energy Reviews (RSER), and Renewable Energy to be the most common (at $60 \%, 9.5 \%$ and $4.1 \%$ of documents, respectively). In the Scopus dataset we found 157 journals, and the top journals were Energy Policy (26\%), Sustainability (Switzerland) (5.3\%), and Renewable Energy (3.4\%). RSER placed fifth, at $2.7 \%$ of publications. Interestingly, the Oil and Gas Journal placed fourth in the Scopus dataset.

This preliminary (and rudimentary) analysis suggests that Scopus does indeed have broader coverage (though of course this could be an artefact of our search criteria), as Wolsink has suggested. Is this additional coverage beneficial? As part of his criticism, Wolsink notes several important papers that he believes should have appeared in our WOS dataset ((Slovic, Flynn, \& Layman, 1991); (Renn, 1998); (Pasqualetti \& Butler, 1987); (Wolsink, 1988); (Thayer \& Freeman, 1987); (Bosley \& Bosley, 1988)). Only the first and the last of these papers show up in the Scopus dataset we constructed. He claims we missed the origins of the field in nuclear power and risks studies. While the Scopus dataset we constructed does contain publications going back to the 1960s, looking only at the titles and abstracts of the 23 papers published prior to 1980, we find only three on nuclear power. Some of the other titles from this era in the Scopus dataset include "Abortions and related medical services in federally assisted programs of the Public Health Service" (Anonymous, 1978), "Impacts of Satellite Power System technology" (Moses, 1979), and "Flavor and color of peas and carrots cooked by microwaves" (Mabesa \& Baldwin, 1978). Wolsink argues we miss the "institutional" take-off in the 1990s and 2000s, but Figure 1 seems not to demonstrate this either. Lastly, the prominence of the Oil and Gas Journal and the author N. Snow (who appears to publish solely in that journal) in the Scopus dataset indicates that a 
dataset constructed in a similar way using Scopus might not have produced a result that would have satisfied Wolsink's broader concerns about "objects of acceptance", explained in greater detail below. So, while the Scopus dataset is indeed larger, whether or not it is as representative of the core field we wished to analyze in the first place (let alone representative of the larger body of literature Wolsink is drawing from) is not self-evident and could benefit from further empirical research.

But, we suggest that going too far down this road risks missing the forest for the trees anyhow. The question is not whether we captured all the literature on social acceptance (or whether our dataset was biased toward some partial segment of it), but rather if we gathered enough to have a sample that afforded us the best balance between specificity (that is, the articles were all actually about the thing we wished to investigate, viz., social acceptance of energy technology and fuels) and inclusivity. Such a balance would be integral to producing results that were intelligible, to building a dataset that our computers would be able to process (once we start analyzing cited references, the size of the dataset grows substantially), but all the while staying close to the original intent of the paper (i.e., visualizing the knowledge domain for social acceptance of energy technology and fuels). We experimented with many different formulations of our search criteria and found the one we used (which produced 857 results) to provide such a balance.

Furthermore, it is important to reiterate that the dataset we constructed to conduct the bibliometric analysis was only a starting point to get at the visualization of research fronts (i.e., the current areas of research activity in this field) and their intellectual bases (i.e., the literature that these fields tend to cite for their foundations). The descriptive analysis was not central to our original aims, but neither (we believe) was it baseless due to our database choice and search criteria. Because both of those citation network analyses look at relationships between articles based on the cited references, the original dataset need not contain every possible article on social acceptance - it need only contain enough relevant articles to produce interesting findings from the (much, much larger) body of literature that is cited by it. As noted above, the citation network included over 30,000 sources

In any event, these methodological concerns are only one half of Wolsink's larger critique about bias. The more pertinent concern is content - what Wolsink terms "objects of acceptance". We turn now to that critique.

\section{"Objects of Acceptance"}

We noted above two other aspects of Wolsink's bias critique: our failure to include institutions in our search criteria, and our decision to restrict our analysis to 'Energy and Fuels'. These are indicative, he argues, of our negligence or mischaracterization of the "objects of acceptance". In formulating the search criteria as we did, he argues we omitted consideration of literature that conceives of acceptance not as 'an aggregation of acceptance by individual citizens' (i.e., public acceptance), but rather as "a bundle of processes of decision-making on issues concerning the promotion of - or counteraction against - new phenomena and new elements in the transformation of current energy systems" (Wolsink, 2018, p. 287). The implication, therefore, is that the 857 articles we used to conduct our citation network analysis is but a small segment of a much larger literature, and a subset that largely mischaracterizes social acceptance as public acceptance.

It is difficult to respond to this criticism. Basically, Wolsink is completely correct in saying we omitted consideration of acceptance of processes/institutional change. Our search criteria included two sets of 
terms: one for the acceptance ('accepta*', 'perception', 'attitud', 'opinion', or opposition), and one for who was doing the accepting ('social', 'public', 'market', 'community', or 'polit*'). So, it is true that we did not include a third set of terms about objects of acceptance (indeed, we stated in our paper that we did not wish to do so in the interest of comprehensiveness). But what would have happened if we had?

The answer is that it would shrink the results. We tested this for this response, using the following search criteria at WOS:

$$
\begin{aligned}
& \text { TS =(accepta* OR perception OR attitud* OR opinion OR opposition) AND TS=(social } \\
& \text { OR public OR market OR community OR polit*) AND TS=(technolog* OR project OR } \\
& \text { institution* OR transition OR change) AND WC=(Energy and Fuels) }
\end{aligned}
$$

Instead of 857 results, we ended up with 618. Restricting that third set of criteria to only 'institution*' returns just 73 results, while searching only 'institution*', 'transition', or 'change' returns 372 . Of course, if we remove the restriction to 'Energy and Fuels', a restriction Wolsink takes explicit issue with, we end up with a much larger result $(47,571$ to be exact). Why didn't we do that originally? As we explained above, we wanted a balanced dataset that didn't obfuscate the literature of interest to us within a much larger pool - a dataset that was explicitly dealing with acceptance of energy technology and fuels, not acceptance of other things. A quick perusal of the top 50 cited papers in that larger result list suggests that obfuscation would be the consequence of proceeding with a dataset like this.

Wolsink also criticizes us for restricting results to the Energy and Fuels category. To quote at length:

Whereas they claim to unfold a 'theoretically and methodologically neutral perspective' (p.142), this may apply to their bibliometric centrality metrics and the sophisticated calculation methods; however, choices in the construction of their original dataset reflect a specific view implying a bias concerning the object of acceptance. A remarkable choice was the selection of words to generate the original dataset based on the restriction to 'acceptance' and to the domain of 'energy and fuels'. GR do not justify this choice, so the 'fuels' element remains unexplained.

Why should fuels, which have been used for a long time and are still dominant define the boundaries of an investigation on social acceptance of new practices, ideas, and technologies? Emerging 'new' energy carriers, such as hydrogen, might justify the focus on fuels, but it is more likely that this choice was dictated by the WoS classification system. As a result, the social acceptance network was partly based on a non-innovative domain, whereas many innovative social acceptance studies are covered by other WoS classifications, such as 'environmental studies' (e.g. Land Use Policy; Global Environmental Change) and 'green and sustainable science and technology' (e.g. Journal of Cleaner Production; Sustainability).(Wolsink, 2018, p. 289)

There are several issues here. For one, Wolsink notes our decision may have been dictated by the WOS classification system. Yes, it was. As such, the exact terms used in the Energy and Fuels category (or indeed any category) were not something we could control. Presumably, the inclusion of 'fuels' in that 
category name by the WOS is meant to capture the vast amount of non-social acceptance energy research on fuels. But, if that research did not include the terms we used for acceptance in the title, abstract or keywords of the article, it would not have appeared in our dataset. Moreover, the analysis of keywords used in our dataset demonstrates that there is no bias toward conventional energy technologies (given that no such terms appeared in the most used keywords). Therefore, the suggestion that the category itself biases the results toward a 'non-innovative' area (a contestable claim in itself) is thus unsubstantiated.

Furthermore, the classification system used by WOS is not exclusive - articles can be classified under multiple categories. We checked the overlap between Energy and Fuels ( 858 articles) and Environmental Studies articles (5693 articles) and found 564 present in both categories. True, there may be more literature on social acceptance in the Environmental Studies category that we did not capture, but - again - our paper aimed to analyse the social acceptance literature on energy technology (the inclusion of 'and fuels' in the title was done to correspond with the search criteria). So Wolsink is indeed correct in noting that we did not consider 'objects of acceptance', but that is because we did not set out to characterize the literature on social acceptance in general.

One final word on the methodology we used to create our original dataset and its implications both for the results we obtained and our ability to interpret them (as discussed in more detail below). We searched under the tag 'TS', which includes titles, abstracts and keywords (both author-supplied and WOS-assigned). Accordingly, our dataset included literature for which the authors themselves saw fit to categorize their own papers as such - this is literature that is 'self-identified' as being about social (and public) acceptance (and perceptions, and attitudes, opinions and opposition). ${ }^{2}$ Far be it for us to argue with authors about whether or not their papers deserve to be included in this amorphous field, nor to add in other terms based on our interpretation of what acceptance entails. If all of the literature that Wolsink is familiar with does not appear in the results of broad-based searches of bibliographic indices at both WOS and Scopus, it seems possible to us that the question of what it is researchers are seeking to analyze has evolved over time, such that earlier researchers did not conceive of their project in the same way as more recent scholars do.

In our 'final thoughts' below, we reflect further on the implications of conceptual evolution for conducting such reviews, but for now we would reiterate that the citation network analysis we conducted was intended to capture that much larger body of literature and portray it as "intellectual basis" (see our 2017 paper for more details). While select papers (e.g., (Thayer \& Freeman, 1987)) may be especially important to some contemporary scholars as a foundational study, the reality is that it just isn't cited by many other current researchers who see themselves as working in this area today.

\section{Interpretation}

The last criticism of Wolsink's that we wish to respond to concerns our interpretation of both the research fronts we identify, and the trends we reflect on in our concluding discussion.

To identify research fronts we conducted a bibliographic coupling analysis, which creates links between articles in our original dataset based on the number of references they share in common (Kessler, 1963).

\footnotetext{
${ }^{2}$ We recognize that it is possible that some journals included in these indices provide suggested keywords to articles, or perhaps do not allow authors to submit their own keywords at all.
} 
We then ran a standard community identification algorithm to identify the top seven such 'fronts'. Wolsink takes issue with the labels we used to identify these fronts and proposes alternative labelling in Table 1 of his paper. Firstly, we would note that Wolsink's alternative labels do not actually appear all that different than ours, and his process for creating his labels is somewhat opaque - he appears to be using the literature we subsequently identified as the intellectual bases for the research fronts, based on his close familiarity with that literature, though the identification of intellectual bases was for us a subsequent step in our research to the characterization of research fronts. This is certainly a legitimate and useful contribution to the interpretation of these fronts, though it was one we were not well-placed to provide, given our interest in proceeding objectively, taking only the terms that were available to us for our 'interpretation'. Our process was simply to take the most frequent keywords used by papers in each research front. So again, we would suggest that if most authors in these fields conceive of these concepts as pertinent for categorizing their own research, it would not be our place to argue with them. Nevertheless, we have no reason to dispute Wolsink's re-interpretation, but note only that his labels were produced based upon his personal familiarity with - and personal perspectives on - the relevant research.

While most of Wolsink's labels are relatively similar to ours, the one that differs the most was Research Front 6, which we labelled as 'communities / renewable energy / policy' and Wolsink labels as 'institutional change, socio-technical systems, community energy'. As it happens, we had similar thoughts about what this research front could contain as Wolsink's label implies, but, given that it was a relatively small front in the bibliographic coupling network, we did not have as broad a base of keywords from which to draw. Had 'institutional change' or 'socio-technical systems' figured more prominently in the results we had, we would have used those for the label of this Front. ${ }^{3}$ Indeed, this was actually the research front that interested us the most, as it seemed to support a perspective on social acceptance (i.e., a focus on politics of institutional change) that most closely aligned with our research aims in a subsequent paper on the socio-political acceptance of energy storage in Ontario (J. Gaede \& Rowlands, 2018). The understanding of social acceptance deployed in this paper appear closer, we believe, to Wolsink's preferred research priorities for the field.

In his subsequent discussion of the other research fronts, Wolsink levies a number of critiques and summaries as to what researchers in those areas are actually doing. We have no basis to dispute his interpretation of this literature, and note only that providing such in-depth, subjective interpretation was not our original intent. Accordingly, Wolsink's discussion here likely serves as a useful, additive perspective on the content of these fronts.

The remaining sections of Wolsink's paper (6 through 9) are more an extended critique of current social acceptance research than our specific paper and so we will not reflect on them here (see 'Final Thoughts' below), except insofar as they concern our concluding 'trends'. Of the three broad conclusions we offered in our 2017 paper, it is only our observation that social acceptance research appears to be shifting from a political to psychological issue that Wolsink takes issue with, though not because he believes that we have misinterpreted the analysis of the data we conducted. Rather, his concern is that this trend, if it exists, is "lethal" for social acceptance research (Wolsink, 2018, p. 292).

\footnotetext{
${ }^{3}$ The reason this Front was smaller was because of the methodology we used to analyse the Fronts, which involved filtering out papers without any couplings and those with coupling weights below 5, which we explain in our 2017 paper.
} 
He does not appear to completely dispute that such a trend might exist, but rather argues persuasively for the importance of resisting such a trend in the interest of attending to structural change (presumably toward sustainability) through social scientific research on social acceptance.

For instance, quoting Upham, Oltra, \& Boso, 2015 (whose framework we found in our earlier paper more comprehensive for categorizing current social acceptance research than the older Wüstenhagen, Wolsink, \& Bürer, 2007 framework), Wolsink draws attention to the possibility that the trend toward a psychological focus may have something to do with the incumbency-preserving interests of funders and policy-makers. He thus poses three challenges to social acceptance researchers:

1. Should we continue research on request of funders, often based on the information 'deficit' model that is known for decades to be invalid for changing environmental behaviour (and not only in the energy domain)?

2. Is the attractiveness of options for policymakers a good guide for acceptance research?

3. Is the prime focus on psychological factors and functioning processes addressing the major issues of social acceptance of innovation?

We do not believe this is the place for us to respond with our personal positions on the issues raised, as it is not clear this is so much a critique of our paper per se as a critique of a subset of social acceptance literature that Wolsink takes issue with (albeit a subset to which he believes we have limited our analysis). We would note, however, that this is a perennial problem for social scientists - one for which we see fit to draw upon Robert Cox's eloquent formulation of the problem in international relations theory.

"Theory is always for someone and for some purpose", Cox wrote in his influential 1981 critique of neorealism, a school of international relations theory typically associated with the work of Kenneth Waltz (and others) (Cox, 1981, p. 128). By this Cox meant that it is not possible for a social scientist to completely divorce themselves from the historical and political context in which they find themselves. As such, one's orientation to the problems they are presented with is a matter of choice: whether to be a problem-solver, taking the world as it is given (i.e., without challenging social/political relationships or the institutions into which they are organized) as a framework for action, or to be critical, to stand apart from the prevailing order of the world and ask how that order came about. "Critical theory", Cox continues:

"does not take institutions and social and power relations for granted but calls them into question by concerning itself with their origins and how and whether they might be in the process of changing. It is directed towards an appraisal of the very framework for action, or problematic, which problem-solving theory accepts as its parameters. Critical theory is directed to the social and political complex as a whole rather than to the separate parts. (Cox, 1981, p. 129)"

To adapt Cox's critique to our current discussion, Wolsink's criticism of our paper - and, by extension, a large swath of current social acceptance research - is that it is overly preoccupied with problem-solving at the expense of being critical. His paper is, as such, a valuable critique directed at all social acceptance researchers (via a critique of our review of their work) to remain mindful of the whole and not get caught up in the 'separate parts' of individual perspectives on new things. 
If this is indeed a characterization that Wolsink would agree with, then we would conclude this review of his critique as follows: we agree. We did not set out to write a critique of social acceptance, as a concept or a research programme, but rather to solve a specific problem stemming within the research project in which we were engaged. Therefore, we welcome Wolsink's critique of our attempt at doing so, as it furthers the discussion and adds a critical lens of a kind that was lacking in our 2017 paper.

\section{Final Thoughts}

Of course, it is necessary to add a few final thoughts, lest we leave readers with the impression that we are content to see the current world order (of social acceptance research, that is) reproduced in perpetuity, or that we fully support Wolsink's characterization of the dilemma facing social acceptance research. There are thus two final challenges we wish to discuss: that of conceptual evolution, categorization and interpretation for academic self-reflection; and that of the real-world constraints that complicate the juxtaposition of problem-solving with critique in the social sciences, particularly as they concern the study of innovation.

We posited above that a potential reason for some of the discrepancy between what Wolsink, a top scholar in the field of social acceptance, expects to see in a dataset on social acceptance literature and what actually appeared in our scans of both the WOS and Scopus indices: that what researchers in this field conceive of as their research topic has evolved over time, such that "social acceptance" (and related terms), have both become both more concrete and intertwined over time. The seminal editorial article by Wuestenhagen et al., (Wüstenhagen et al., 2007) was no doubt integral in the formalization of "social acceptance" as a concept and research programme, and thus one which subsequent researchers typically see necessary to cite and to categorize their own work accordingly. In essence, "social acceptance" could not be a concept before it became one, and so earlier researchers may or may not have conceived of their project in this way. Because of the nature of database search criteria, it is not always possible to capture the research that is pertinent, though not specifically labelled as such, in a preliminary dataset of articles on a given topic. We tried to be as comprehensive as we could be in formulating our original search criteria, though as Wolsink's criticisms and the above analysis indicate, it is possible that there are some ancillary and closely-related articles that are influential in the field of social acceptance, but not explicitly labeled as such.

However, as stated above, we believe that our original dataset was nonetheless sufficiently balanced (i.e., targeted) as to produce a representative collection of articles on which to conduct the bibliometric analysis we did. As described above, this analysis (particularly the co-citation analysis) utilizes a dataset of referenced articles that is vastly larger than the original 857 articles contained in our dataset. The argument that a non-exhaustive starting dataset would have constrained our ability to identify influential intellectual bases is thus difficult to accept. It seems more likely to us that many researchers working on social acceptance issues today simply do not see institutions, transitions and social change as an integral part of their research programme.

If that is the case, that does not weaken Wolsink's call for social acceptance research to remain mindful of the more complex and wholistic understanding of social acceptance that he advances - in fact it strengthens it. We agree with Wolsink that a critical approach to the question of energy technology and system social acceptance necessitates attention to "the whole", somewhat akin to what he has outlined in his paper. Where we disagree, however, is that all research on social acceptance needs to adopt the same conceptual framework, the same "single and comprehensive structure" (to quote 
ourselves from above), for understanding what social acceptance is and what a research programme for it should entail. Indeed, insofar as we, being critical social scientists, wish not to be caught up with the "separate parts", we should embrace and engage with a diversity of perspectives as it is these, when taken together, that truly constitute the whole of social acceptance research (even if we might not all agree on some of the basics).

Interpretation and categorization are therefore inevitably bound to be partial and imperfect reflections of the larger, amorphous, evolving whole, as no totalizing framework is able to encompass (in a coherent way) its inherent lack of uniformity. This is as true of our own analysis as it is of Wolsink's, and of the research categorizations used by individual authors (i.e., keywords) and the bibliographic databases like Scopus and WOS. Two terms - both with neutral, analytical definitions, but also (and often) political connotations - were raised in Wolsink's critique and our response, respectively: bias and objectivity. In actuality, these are two sides of the same coin. In our desire to produce "as comprehensive and neutral" (i.e., as objective) an overview of the field as possible, we resisted interpretation of the content as much as was possible. Wolsink's paper has, if nothing else, reminded us that this approach had a trade-off: as we had to rely on self-identification and categorization to do so, we sacrificed interpretative depth and thus our findings may have been (unintentionally) biased toward whatever subset (categorization, interpretation) of the field happened to be in ascendancy at the moment (for whatever reason). We submit, however, that Wolsink faces the same trade-off, and in choosing the opposite approach (subjective interpretation based on deep familiarity), is still biased toward a particular view.

This brings us to our final issue - the perennial challenge to social science of choosing either to reconstitute the world in all its imperfections (i.e., to be a problem solver), or to struggle against those imperfections in pursuit of a better one (i.e., to be critical). Despite the lengthy intellectual heritage of this challenge ("Philosophers have hitherto only interpreted the world in various ways; the point is to change it" (Marx, 1978)), we question whether posing this challenge is beneficial to the conduct of social scientific research on social acceptance, particularly concerning innovation and especially as it concerns the sustainability of energy systems.

Wolsink's three questions raise important issues concerning the extent to which research may be shaped by extraneous factors with little interest in or care for critical assessment of complex social and/or political structures and processes. These are issues that each individual researcher must grapple with. Should we expect that they all answer them in the same way, regardless of academic discipline, intellectual heritage, departmental policy, stage of career, or research interests? Moreover, is attendance to the interests of policymakers and grant administrators necessarily detrimental to the conduct of critical social science for social acceptance? To both questions we would answer no. Insofar as social acceptance research tends to be concerned with innovation (be it technological or systemwide), and innovation is inherently about change from the present, it seems to us that even problemsolving oriented research on the topic is beneficial in pursuit of a more sustainable future. The stakes are too high to restrict the ways we can build greater understanding of this topic.

It is perhaps a truism to note that the value of academic research for non-academic audiences lies mostly in its practical implications. It should therefore be seen as a testament to the practical contributions of social acceptance research to date that such concerns are now firmly "on the radar" for policy-makers, project developers, grant administrators and so forth. Yet progress in this area has and 
will continue to rely on critical assessment as well, both of the nature of the thing we are investigating and of our own work, and so we welcome Wolsink's prompting to do so.

\section{References}

Anonymous. (1978). Abortions and related medical services in federally assisted programs of the Public Health Service. Federal Register, 43(141), 31868-31879.

Bosley, P., \& Bosley, K. (1988). Public acceptability of California's wind energy developments: three studies. Wind Engineering, 311-318.

Cox, R. (1981). Social Forces, States and World Orders: Beyond International Relations Theory. Millennium: Journal of International Studies, 10(2), 126-155.

Doll-Steinberg, A., \& Moss, J. (1968). The post-war mode of development of the European petrochemical industry. Preprints, 13(4).

Gaede, J., \& Rowlands, I. H. (2018). How 'transformative' is energy storage? Insights from stakeholder perceptions in Ontario. Energy Research and Social Science, 44, 268-277. https://doi.org/10.1016/j.erss.2018.05.030

Gaede, James, \& Rowlands, I. H. (2018). Visualizing social acceptance research: A bibliometric review of the social acceptance literature for energy technology and fuels. Energy Research \& Social Science, 40, 142-158. https://doi.org/10.1016/j.erss.2017.12.006

Hirmer, S., \& Cruickshank, H. (2014). The user-value of rural electrification: An analysis and adoption of existing models and theories. Renewable \& Sustainable Energy Reviews, 34, 145-154. https://doi.org/10.1016/j.rser.2014.03.005

Kessler, M. M. (1963). Bibliographic coupling between scientific papers. American Documentation, 14(1), $10-25$.

Mabesa, L. B., \& Baldwin, R. E. (1978). Flavor and Color of Peas and Carrets Cooked by microwaves. Journal of Microwave Power, 13(4), 321-326. 
Marx, K. (1978). Theses on Feuerbach. In R. C. Tucker (Ed.), The Marx-Engels reader (2nd ed., pp. 143145). New York: Norton.

Moses, H. (1979). Impacts of satellite power system technology. Energy, 4(5), 799-809.

Pasqualetti, M. J., \& Butler, E. (1987). Public reaction to wind development in California. International Journal of Ambient Energy, 8(2), 83-90.

Renn, O. (1998). Three decades of risk research: accomplishments and new challenges. Journal of Risk Research, 1(1), 49-71.

Slovic, P., Flynn, J. H., \& Layman, M. (1991). Perceived risk, trust, and the politics of nuclear waste. Science, 254(5038), 1603-1607. https://doi.org/10.1126/science.254.5038.1603

Thayer, R. L., \& Freeman, C. M. (1987). Altamont: Public perceptions of a wind energy landscape. Landscape and Urban Planning, 14, 379-398. https://doi.org/10.1016/0169-2046(87)90051-X

Unruh, G. C. (2000). Understanding carbon lock-in. Energy Policy, 28(12), 817-830. https://doi.org/10.1016/S0301-4215(00)00070-7

Upham, P., Oltra, C., \& Boso, À. (2015). Towards a cross-paradigmatic framework of the social acceptance of energy systems. Energy Research \& Social Science, 8, 100-112. https://doi.org/10.1016/j.erss.2015.05.003

Wolsink, M. (1988). The social impact of a large wind turbine. Environmental Impact Assessment Review, 8(4), 323-334.

Wolsink, M. (2018). Social acceptance revisited: gaps, questionable trends, and an auspicious perspective. Energy Research \& Social Science, 46, 287-295. https://doi.org/10.1016/j.erss.2018.07.034

Wüstenhagen, R., Wolsink, M., \& Bürer, M. J. (2007). Social acceptance of renewable energy innovation: An introduction to the concept. Energy Policy, 35(5), 2683-2691. https://doi.org/10.1016/j.enpol.2006.12.001 
